\title{
Epidemiology of dermatological diseases - aging, metabolic diseases and beyond
}

\author{
Pierre A. Guertin* \\ Department of Psychiatry and Neurosciences, Laval University Medical Center - CHU de Quebec, Canada
}

\begin{abstract}
More than forty different diseases are associated with dermato-pathological problems. The skin is the largest organ of the body - as any organ, its constitutive elements are, under physiological conditions, controlled by signals arising from the central, peripheral and autonomous nervous systems. Consequently, a plethora of problems affecting central nervous system (CNS) and non-CNS-mediated functions may lead secondarily to skin problems. As of now, the industry has generally failed to provide safe and potent drugs and therapeutics capable of fulfilling each of these specific unmet medical needs - most skin care products don't even meet safety standards and requirements, as imposed by regulatory authorities for approval and marketing of pharmaceutical products (i.e., small molecule therapeutics or biologics). Thus, next-generation drugs ant therapeutics for skin diseases will probably be increasingly acting upon central and peripheral mechanisms for superior efficacy which, in turn, shall force regulatory authorities to impose stricter regulations for approval and marketing of dermatological products.
\end{abstract}

\section{Introduction}

The skin is the largest organ of the body and the first line of defense against external pathogens. Dysfunctional skin is in fact associated with several debilitating pathological conditions such as xerosis and atopic dermatitis (see complete list below) [1] (Table 1).

The International League of Dermatological Societies (ILDS) has identified the consequences of skin aging as one of the most important grand challenges in global skin health [2]. As we get older, the skin undergoes significant changes - many of which may be attributed to systemic, metabolic, and lifestyle changes. According to the World Health Organization, the number of people aged 65 or older is projected to grow from 524 million (2010) to nearly 1.5 billion in 2050 (who.int/ ageing). However, the incidence of those who will be dealing with skin problems remains unknown. Other underlying conditions or diseases are also known to alter skin health. Environmental problems such as pollution negatively affect skin health (see complete list below (Table 2)). Diabetes is also a leading cause skin problem. Skin disorders, usually neglected and frequently underdiagnosed among diabetic patients, are common complications and encounter a broad spectrum of disorders in both type 1 and type 2 diabetes mellitus - e.g. cutaneous infection, dry skin, pruritus. Skin disorders are highly associated with increased risk of important outcomes, such as skin lesions, ulcerations

Table 1. Pathological conditions of dysfunctional skin.

\begin{tabular}{|c|c|c|}
\hline xerosis & sebaceous cyst & vitiligo \\
\hline atopic dermatitis & seborrheic keratosis & lupus \\
\hline skin cancer & pilonidal sinus & eczema \\
\hline hemangioma & ichthyosis vulgaris & impetigo, abscess \\
\hline cold sore & psoriasis & decubitus ulcer \\
\hline cutaneous candidiasis & rosacea & herpes \\
\hline carbuncle & hives & fungal nail infection \\
\hline acne vulgaris & hypodhidrosis & pruritus \\
\hline alopecia areata & fungal skin diseases & non-melanoma skin cancer \\
\hline decubitus ulcer & cellulitis & psoriasis \\
\hline urticaria, scabies & molluscum contagiosum & sun burn \\
\hline
\end{tabular}

and diabetic foot, which can lead to major complications and revolve around multifactorial factors besides hyperglycemia and advanced glycation end products [3].

Physicians are aware that climatic conditions negatively affect the skin. Low humidity and low temperatures lead to a general decrease in skin barrier function and increased susceptible towards mechanical stress. Since pro-inflammatory cytokines and cortisol are released by keratinocytes, and the number of dermal mast cells increases, the skin also becomes more reactive towards skin irritants and allergens [4]. Regarding prevalence, skin diseases may be considered one of the greatest problems of all time. For instance, according to data from NIAMS (National Institute of Arthritis and Musculoskeletal and Skin Disease), more than 5.5 million people in the U.S. suffer of psoriasis, 17 million live with acne and 5 million with vitiligo. According to the British Skin Foundation, 8 million people in the U.K. are currently living with one of the skin diseases. Several

Table 2. Factors affecting the skin disorders.

\begin{tabular}{|c|c|c|}
\hline andropause-aging & brain swelling & pressure \\
\hline menopause-aging & glaucoma & friction \\
\hline diabetes & obesity & mobility problems \\
\hline environment & malnutrition & paralysis \\
\hline climatic conditions & epilepsy & vascular problems \\
\hline lifestyle & pharmaceutical products & arthritis \\
\hline epigenetics & depression & Alzheimer's disease-aging \\
\hline viral infection & inflammatory diseases & dementia \\
\hline drug abuse & cardiovascular diseases & herpes \\
\hline cancer & infectious diseases & - \\
\hline
\end{tabular}

Correspondence to: Pierre A Guertin, Department of Psychiatry and Neurosciences, Laval University Medical Center - CHU de Quebec, Canada, E-mail: pierre.guertin@crchul.ulaval.ca

Received: November 17, 2016; Accepted: November 28, 2016; Published: December 02, 2016 
cellular mechanisms, either CNS or non-CNS related may underlie skin diseases and pathological conditions. Dysregulation of skin receptors (nociceptor, mechanoreceptor, etc.) may constitute one of the problems. They normally send directly or indirectly to the central nervous system, inputs involved in assessing hot/cold, pressure/touch, pain, vibration, or chemicals as well as vasocontraction, vasodilatation, body temperature regulation, barrier function, secretion, growth, differentiation, cell nutrition, nerve growth, inflammatory and immune responses, apoptosis, proliferation, and wound healing [1]. Water transport problems may also underlie skin, and particularly dry skin problems. Water content levels depend indeed on water transport from inner layers, including from blood vessels, seeks bringing in water towards the dermis and, hence, the epidermis. Once SC layer is reached, water is eventually being lost to evaporation. Consequently, to decrease water content losses, it is imperative to limit evaporation and sweating in some conditions. Aquaporin channels, supported by waterbinding molecules such as glycerol, expressed on vascular endothelial cells, facilitate water exchange and transport between blood and dermis [5]. Blood volumes, circulating flow levels and regional distribution are directly affecting water transport levels [6]. Actions upon these systems critically depend upon a complex variety of neural mechanisms - i.e., hypothalamic-pituitary-adrenal axis (e.g., arteriovenous anastomoses) raphe nucleus, medulla oblongata, preoptic area, hypothalamus, pons and periaqueductal gray matter [7-11]. Recording skin sympathetic nerve activity has revealed that a large fraction of the sympathetic activity during heat stress is essentially sudomotor in nature through acetylcholine release that binds to muscarinic receptors. Other neural systems may be involved (e.g., $\alpha$ - or $\beta$-adrenergic, vasoactive intestinal polypeptide, calcitonin gene-related peptide) [12-14]. The human skin and its sebaceous glands express a plethora of neuropeptidergic receptors - e.g., corticotropin-releasing hormone, transient receptor potential vanilloid-1, melanocortins, $\beta$-endorphin, vasoactive intestinal polypeptide, neuropeptide $\mathrm{Y}$, substance $\mathrm{P}$, and calcitonin gene-related peptide which may become dysfunctional or with altered expression levels $[15,16]$.

Other main pathological conditions known for altering skin cells and functions include brain swelling, glaucoma, epilepsy, obesity, malnutrition and cancer [17-22]. Unfortunately, most related mechanisms are, as of now, only considered as future cellular targets for next-generation CNS or non-CNS products against specific skin disease or dry skin problems. It will be pivotal for scientists to rapidly identify and develop potent therapies adapted to each condition for ensuring that skin and dry skin problems could, one day, be efficiently and safely treated.

\section{References}

1. McGrath JA, Eady RA, Pope, F.M (2004) Rook's Textbook of Dermatology (7th ed.). Blackwell Publishing. pp. 3.1-3.6.
2. Blume-Peytavi U, Kottner J, Sterry W, Hodin MW, Griffiths TW, et al. (2016) AgeAssociated Skin Conditions and Diseases: Current Perspectives and Future Options. Gerontologist 56: S230-S242. [Crossref]

3. de Macedo GM, Nunes S, Barreto T (2016) Skin disorders in diabetes mellitus: an epidemiology and physiopathology review. Diabetol Metab Syndr 8: 63 [Crossref]

4. Engebretsen KA, Johansen JD, Kezic S, Linneberg A et al. (2016) The effect of environmental humidity and temperature on skin barrier function and dermatitis. $J$ Eur Acad Dermatol Venereol 30: 223-249. [Crossref]

5. Papp A, Romppanen E, Lahtinen T, Uusaro A, Harma M, et al. (2005) Red blood cell and tissue water content in experimental thermal injury. Burns 31: 1003-1006. [Crossref]

6. Krogstad AL, Elam M, Karlsson T, Wallin BG (1995) Arteriovenous anastomoses and the thermoregulatory shift between cutaneous vasoconstrictor and vasodilator reflexes. J Auton Nerv Syst 53: 215-22.

7. Blessing WW, Yu YH, Nalivaiko E (1999) Raphe pallidus and parapyramidal neurons regulate ear pinna vascular conductance in the rabbit. Neurosci Lett 270: 33-36. [Crossref]

8. Key BJ, Wigfield CC (1994) The influence of the ventrolateral medulla on thermoregulatory circulations in the rat. J Auton Nerv Syst 48: 79-89. [Crossref]

9. Ootsuka Y, Terui N (1997) Functionally different neurons are organized topographically in the rostral ventrolateral medulla of rabbits. J Auton Nerv Syst 67: 67-78. [Crossref]

10. Owens NC, Ootsuka Y, Kanosue K, McAllen RM (2002) Thermoregulatory control of sympathetic fibres supplying the rat's tail. $J$ Physiol 543: 849-858.

11. Shibasaki M, Wilson TE, Crandall CG (2006) Neural control and mechanisms of eccrine sweating during heat stress and exercise. J Appl Physiol 100: 1692-1701. [Crossref]

12. Schmelz M, Schmidt R, Bickel A, Torebj0rk HE, Handwerker HO (1998) Innervation territories of single sympathetic C fibers in human skin. J Neurophysiol 79: 1653-1660. [Crossref]

13. Schutz B, Schafer MK, Gordes M, Eiden LE, Weihe E (2015) Satb2-independent acquisition of the cholinergic sudomotor phenotype in rodents. Cell Mol Neurobiol 35: 205-216. [Crossref]

14. Zouboulis CC (2004) Acne and sebaceous gland function. Clin Dermatol 22: 360-366. [Crossref]

15. Toyoda M, Nakamura M, Morohashi M (2002) Neuropeptides and sebaceous glands. Eur J Dermatol 12: 422-427. [Crossref]

16. de Macedo GM, Nunes S, Barreto T (2016) Skin disorders in diabetes mellitus: an epidemiology and physiopathology review. Diabetol Metab Syndr 8: 63. [Crossref]

17. Danby SG (2016) Biological Variation in Skin Barrier Function: From A (Atopic Dermatitis) to X (Xerosis). Curr Probl Dermatol 49: 47-60. [Crossref]

18. Verkman AS (2009) Knock-out models reveal new aquaporin functions. Handb Exp Pharmacol : 359-381. [Crossref]

19. Giacomoni PU, Rein G (2004) A mechanistic model for the aging of human skin Micron 35: 179-184. [Crossref]

20. Vinik AI, Maser RE, Mitchell BD, Freeman R (2003) Diabetic autonomic neuropathy. Diabetes Care 26: 1553-1579. [Crossref]

21. Russell M (2012) Assessing the relationship between vitamin D3 and stratum corneum hydration for the treatment of xerotic skin. Nutrients 4: 1213-1218. [Crossref].

Copyright: (C2016 Guertin PA. This is an open-access article distributed under the terms of the Creative Commons Attribution License, which permits unrestricted use, distribution, and reproduction in any medium, provided the original author and source are credited. 